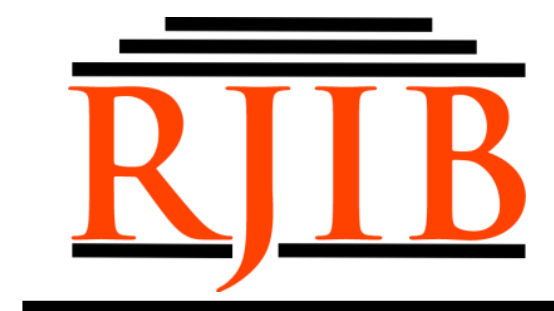

RETORIKA: Jurnal Ilmu Bahasa

Vol. 7, No. 2 October 2021, Page 185-190

\title{
Orders of Signification and Elements of Mythology of Educational Quotes
}

\author{
Rovita Jayaning Shoimmah ${ }^{1}$, Rohmani Nur Indah ${ }^{2}$ \\ ${ }^{I}$ State Islamic Institute of Kediri \\ ${ }^{2}$ Universitas Islam Negeri Maulana Malik Ibrahim Malang \\ tatavita28@gmail.com
}

P-ISSN: 2406-9019

E-ISSN: 2443-0668

Available Online at https://ejournal.warmadewa.ac.id/index.php/jret

\begin{tabular}{|l|}
\hline How to cite (in APA style): \\
Published: 15/10/2021 \\
Shoimmah, R. J. \& Indah, R. N. (2021). Orders of Signification and Elements of Mythology of Educational Quotes \\
Retorika: Jurnal Ilmu Bahasa, 7(2), 185-190. doi: https://doi.org/10.22225/jr.7.2.2776.185-190
\end{tabular}

\begin{abstract}
Quote in education, expanding positive messages aimed at everyone in achieving success that can be considered a social perspective. Education quotes consist of verbal and non-verbal elements to deliver messages in communication. Quotes play an important part in social communication, including analyzing and interpreting messages communicated with nonverbal meaning. This study aims to find the meaning of denotation and meaning of connotation in some quotes from an Internet web and to find the meaning of verbal and non-verbal elements in the image used as the background of these quotations. This research is qualitative descriptive research in content analysis. This means that it does not require a statistical approach to investigating the data. Researchers use Roland Barthes's theory in semiotics to know the meaning of the educational quotation in analyzing data. By analyzing the data, there are two findings of this study. The first findings show two commands to investigate the meaning, which is domestic and connotative meaning. This study's second findings reveal that mythology in educational quotes is analyzed on verbal and non-verbal elements in each image.
\end{abstract}

Keywords: Mythology, Quote, Semiotics

\section{INTRODUCTION}

Communication is done with two directions directly, but communication can also be done in one way. When the message can send the message, but the recipient of the message cannot provide feedback from the message, it is called a one-way communication. Communication is an essential thing in social life. Spreading knowledge and information to others is done through communication. Various information can be shared through various media such as books, newspapers, magazines, print media, and social media that everyone can reach more easily. Everything is also made by an attractive fabulous by adding interesting things associated with social communications in the Millennial Era. One interaction of social relationships and groups of groups that have been a favorite in various circles is communication through social media (Mirsarraf et al., 2017). Social Media is also considered more interesting and can be connected to all people in different parts of the world without considering the distance. Many communities use social media as a means of communication and sharing information. Social media's current communication purposes have now become a human need that appears with diverse platforms to the type (Payuk \& Zakrimal, 2020).

At this time, communication can be verbal and non-verbal text to deliver messages to others. In social communication, there is a diverse meaning of verbal and non-verbal aspects (Layng, 2016). Virtual literature has 
been developed widely in the context of technology, globalization, and communication. In analyzing the verbal object, this study discusses the message delivery in education. It aims to improve textual analysis skills against an object containing images along with text or sentences as a description. Representation in general writing and image is also done to analyze the lines, colors, and more specific symbols.

The science of semiotics is needed to support the understanding of the signs and messages contained in an image as a research object because the science of semiotics is a science that studies the meaning of signs (Payuk \& Zakrimal, 2020) objects, lines, colors, and images. There is a term signifier, signifier, and signified, which means markers in semiotics (Mazidah, 2018). The signifier or marker leads directly to the mark, while the signifier leads to the marked object. Besides, there is also the term fashion, which is the grouping of references in the science of semiotics culturally. According to Kress's theory, the combination of different modes in creating meaning has become a possibility when understanding the text, even the linguistic part. We must have a clear idea that some features or other parts may also play a role in interpreting the text. Various objects that can be analyzed in semiotics can be pictures on children's books, book covers, magazine covers, posters, advertisements, etc.

Approaches, methods, and theories have the main strengths and advantages in dissecting literary works deeply because it is better to improve the theory forth by other characters (Jagalimu \& Kasni, 2018). When analyzing signs in semiotics, it is not just about anything that is in a picture, but also the meaning contained in the elements that are in the object. Barthes' concept of mythology is related to the meaning of images or photos (Ala, 2011). The concept of mythology is the meaning of objects through sentences or meanings that often appear regarding the object. In addition to the concept of mythology, Barthes also applies denotative and connotative encounters in Signification orders. The semiotics theory is divided into two parts of the meaning, and the first is a verbal sign like expression and phrases, while the second is a non-verbal sign of text and images. This semiotic analysis introduces new challenges to media communication through the connotative analysis and speaking to explain how media can produce the meaning of the system sign (system sign). The image analyzed can lead to many patterns connected between semiology and media through analysis initiated by this Barthes.

The concept of mythology is the meaning of objects through sentences or meanings that often appear concerning these objects. Apart from the concept of mythology, Barthes also applies denotative and connotative meanings in orders of signification (Mazidah, 2018). The semiotics theory is divided into two parts of the meaning, and the first is a verbal sign like expression and phrases, while the second is a non-verbal sign of text and images. This semiotic analysis introduces new challenges to media communication through the connotative analysis and speaking to explain how media can produce the meaning of the system sign. The image analyzed can lead to many patterns connected between semiology and media through analysis initiated by this Barthes.

Through pictures, readers can know the meaning deeper than just reading the text. Pictures help readers to understand the most connotative meanings. Researchers believe that semiotics analysis is very suitable for analyzing signs and that this can help readers interpret other images within the scope of semiotics. Besides, digital photography, graphics, and print media technology can be combined into one and explained precisely where it was not done 20 years ago (Mavers, 2004). It is now embodied in the posters and quotes of experts. Text and images can be different and even reversible when representing meaning. So not all citations on social media may be related to verbal and non-verbal meanings.

In this study, researchers make a difference using quotations from figures accompanied by images as objects analyzed. The exporter of the quotation is a medium of one-way communication where the reader cannot reply to the message's contents to the author. Researchers choose quotations related to education because it can deliver messages to anyone in achieving success when developing and enriching their knowledge. Quotes can affect students to see a new perspective in beneficial and not boring education and see the perspective of academic success that is possible to achieve (Collins, 2016). Researchers do not find much relevant earlier research in education, especially in analyzing the 
characters' quotes as the object of research. Quotes can also be wise words from many communities' known figures to motivate in doing so better. The image accompanies most of the quotes spread across the community to support the quote's meaning to help the readers capture meaning more in-depth.

There are some previous studies related to semiotics research that researchers use as a reference. Previous researchers have researched in the social field with various objects such as cartoon images, magazine covers, batik cloth Toba and even graffiti on the back of the truck. Research on cartoons as objects is done by (Shadiqi, 2014) entitled Semiotic Analysis of South Park Cartoon 1. This study shows that South Park cartoons can be considered discourse learning (discourse) through semiotic analysis because it often gives criticism and ideas to build social culture. Meanwhile, a study entitled A Semiotic Analysis of the Representation of Indonesian Muslim Women on ANNISA Magazines Front Covers was conducted by (Putri \& Arimbi, 2015). Both researchers made the cover of Annisa magazine an object of study. The results show that Muslim women are represented as bodies, stylish, modern, and pious women. As a Muslim women's magazine, Annisa has a specific purpose of spreading the concept of Muslim women's beauty.

The next study chose the Ulos Batik Toba cloth as an object analyzed by (Situmorang, 2014). The study was titled Semiotics Analysis on Color Symbols in Tobanese Batak Ulos, with results claiming that the Ulos Toba cloth has differentials of each other. The difference is in the name, color, motif, and user of the fabric. According to the Toba community, color is an essential element in the life of the Batak tribe. On the other hand, (Mazidah, 2018) has conducted a semiotic analysis of the dump trucks and proves that various meanings result from the graffiti in the back tub. The meaning found is denotative and connotative, and there is also the concept of mythology resulting from the sound of the connotative.

In the image, semiotics can also be used to analyze the wider field as done by (Berek, 2018) by researching the traditional ceremony of Kawen Sai, and he examines the various terms used in the customary ceremony. In this study, he used the science of semiotics to find the meaning contained in related terms.

This research is done to contribute to learning in the field of semiotics. Researchers are doing this research in order to develop knowledge in the field of semiotics, which is still rare in demand. In contrast, knowledge of semiotics is essential to understand the meaning of an image/sign. In research conducted by (Mayr, 2013), semiotics is very important in life to help us know the original meaning of an object/image. The science of semiotics is needed to interpret the sign (sign) and how the sign affects human life (Payuk \& Zakrimal, 2020).

The aims of researchers implementing this study is to find the analysis results related to the meaning of denotation and meaning of connotation in some quotes from an Internet web. This is needed because to help the readers in discovering some quotes in the world of education. By understanding the meaning, readers can easily make the meaning of the question that the writer delivered by the author. Besides, researchers also want to find the meaning of verbal and non-verbal elements in the image used as the background of these quotations. The elements contained in the image also have related meaning or meaningful meaning with some of the quotes.

\section{METHOD}

The purpose of researchers implementing this study is to find the analysis results related to denotation and connotation meanings in some quotes from an Internet web. This is needed because to help the readers in discovering some quotes in the world of education. By understanding the meaning, readers can easily make the meaning of the question that the writer delivered by the author. Researchers also want to find the meaning of verbal elements and non-verbal elements in the image used as the background of these quotations. The elements contained in the image also have related meaning or meaningful meaning with some of the quotes.

The research method is included in qualitative descriptive research in the content analysis because researchers conduct a direct analysis of research objects. Qualitative research uses observation and survey to collect data (Nassaji, 2015). In qualitative research, there are many advantages of data collection through instruments with humans compared with non-human instruments (Latief, 2015). Therefore, this research is qualitative with direct observation conducted by researchers, so 
researchers are the key to the instrument. It acts as a contradiction, interviewer, data analysis, and reporter in this study. The data used by researchers is a quote in the education of taken from a web named Quotefancy.com. Based on (Rasyid, 2015) triangulation is a technique to test the researcher's national call data analysis. This research uses methodology because there are three methods to be done interviews, observations, and surveys.

Researchers use semiotics theory by Barthes to analyze the data to comment on the discussion of signs and meanings by this study's purpose. Researchers analyze text to find connotative and denotative meanings. Then researchers also analyze images using mythology concepts. Both concepts of analysis are based on the semiotic theory put forward by Barthes. Researchers also use some supporting references such as books, scientific articles, and some previous research relevant to this research topic to analyze the data that has been collected.

\section{RESULT AND DISCUSSION}

The data obtained by the researcher is analyzed in two parts. The first part analyzes the denotative and connotative meanings in the text in the quotation, while the second part analyzes the image according to the mythological concept.

\section{Connotative and denotative meaning}

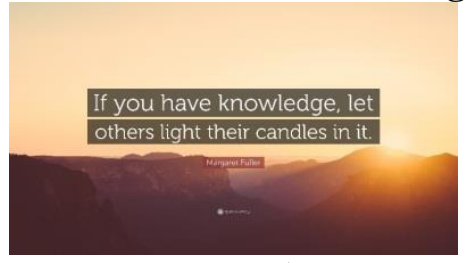

Images 1

The sentence found in the first quote is, if I know, let others this candles in it this connection is meaningful, if someone has science/knowledge, he should allow others to learn the science so that others can feel the benefits. In this quote, the researcher takes the word candle (candle) who has the meaning as a science or knowledge. This is caused if someone in the darkness will need a candle as the light of the light and someone who opens the folly then he will be able to convince the science/knowledge to be his life better.

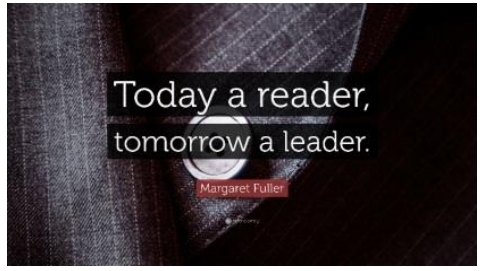

Image 2

In the second quote, there is the sentence today a reader, tomorrow a leader. "Which means connotative if someone as a reader today can be a leader tomorrow. In this sentence, the researcher takes the word reader (reader), which has the meaning of a student/learner. The term reader is very synonymous with students who always prioritize reading to gain knowledge. By being a student who loves to read, students gain much knowledge for the future to become successful people. A successful person is one who can lead himself to face real life with the knowledge he has.

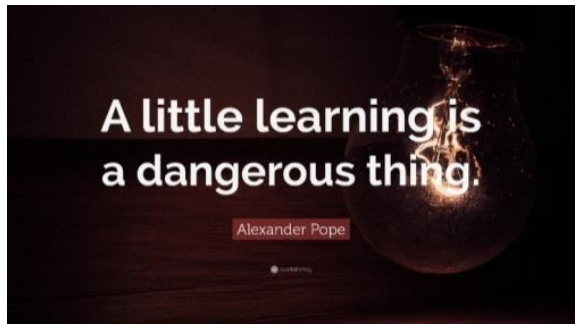

Image 3

The third quote contains a few Little Learning $\mathrm{A}$ is a dangerous thing meaningful if some are a bit of learning, then it will harm his own life. In this sentence, the researchers took the word dangerous (a danger) who had the meaning of the problem. When someone only has a little knowledge of something, it would be dangerous to make an incorrect decision due to the lack of science studied. A little bit will learn will only get a little knowledge, so while facing a problem, making decisions that even harm themselves.

\section{Mythology}

To find the meaning of images used in quotations, researchers use the concept of mythological theory by Barthes. In this theoretical concept, the data obtained (images) are analyzed based on verbal and non-verbal elements.

Figure 1: Mythology based on verbal elements in figure 1 in the form of quoted text. This shows someone who has enough knowledge to 
share with others. He hopes that the knowledge he has can help others to achieve their goals. This illustration is illustrated by the word candle used to illuminate in the dark. The candle describes the knowledge disseminated.

While mythology is based on non-verbal elements in pictures of scenery in the mountains, a sun describes science as a bright light. Every human being can pass darkness if they have light. On the other hand, light is symbolized by the sun, which has unlimited light capacity. Similarly, with unlimited knowledge, when knowledge is shared, it will never run out.

Figure 2: Based on the verbal elements in picture 2 in the form of text, this picture's mythological concept is made to motivate students to become excellent readers. When students can apply a leading reader's attitude, it will be a great leader in the future. Because good leaders have the ability to read situations, read opportunities, and even read the risks they will face. Every human being is also a leader for himself, leading to having a respectful attitude, discipline, confidence, and wisdom.

On the other hand, non-verbal elements in the form of images show black coats as formal attire mostly used by leaders informal events. The color of dark clothing reflects strength. In the general public, dark colors represent formality, quality, strength, and power.

Figure 3: Analyzed from the quoted text as a verbal element, the quotation is aimed at students to learn more actively. The sentence in the quotation states that a person who only seeks learning will gain little knowledge. Such a little knowledge can lead to misunderstandings in a particular science/concept theory.

In the analysis of images as non verbal elements in this quote, there is a description of the atmosphere of darkness with little explanation. The atmosphere of darkness is chosen as an illustration of human life, and the dim light of a light bulb reflects little/limited knowledge. The concept of mythology in this picture explains that a person who only learns a little science will endanger himself and cannot make the right decisions when faced with a problem. Even the knowledge he has cannot help illuminate his life path because it is considered still lacking.

By doing this research, the researcher aims to find the meaning of educational quotations on a web called quotefancy.com. This study's findings show that there are two specific meanings in finding the meaning of quotations, namely through connotative meaning and denotative meaning. These findings prove the theory put forward by Barthes that in semiotics, there are two specific meanings, namely through connotations and denotations. This finding is also in line with previous research conducted by (Shadiqi, 2014) entitled Semiotic Analysis of South Park Cartoon Comedy Season 1". Previous research findings also show that sentences in the dialogue are analyzed through two meanings, namely connotative meaning and denotative meaning

Besides, the researchers in this study conducted an analysis of mythology, which Barthes put forward. Based on the theory put forward by Barthes, mythology is conceptualized to interpret the meaning of images through connotative meanings on verbal elements and non-verbal elements in an image finding in this study prove that in the analysis analyzed there are two elements in each image, verbal elements and non-verbal elements represented by images as backgrounds. The results of this study are in line with previous research entitled "Indonesian Muslim Women on ANNISA Magazines Front Cover (Putri \& Arimbi, 2015) as well as research entitled Semiotic Analysis on the Graffiti of the Dump Trucks " (Mazidah, 2018) which using the concept of mythology based on Barthes' theory.

The use of images as the background of educational citations has a special meaning, as found in this research. However, this does not mean that the image always supports the core of the message. This is as found by Xiong and Peng (2020). Without the proper selection of elements, images cannot support the digging effort of interpreting cultural meanings representing the citation in question.

By analyzing all educational quotes and their elements, it can be concluded that the quotes in the field of education are aimed at students to lead to the importance of education in real life and motivating them to learn more to get a bright future. With education, one can change how to think it gets better, wisely in life, and more learned because of the deeper knowledge and knowledge. Education is the science and knowledge gained in schools and the various attitudes, behavior, and moral messages obtained in any human being's everyday life. 


\section{CONCLUSION}

The findings and discussions presented in the previous chapter show that there are two meanings found in the citation of education, namely denotative and connotative meanings. The denotative meaning is in the first order, and the connotative meaning is in the second layer. Besides, researchers are also investigating the meaning of mythology in educational quotes in quotefancy.com. This study's findings reveal that there are two elements in each citation in educational citations, the verbal element represented by the quotation and the non-verbal element represented by the image as the background. Next, the two elements in each citation are analyzed by applying the concept of mythology.

Researchers want to provide some suggestions related to the educational quotes in quotefancy.com, which may help everyone learn or do research. Researchers suggest the next researcher better than this research by adding the uniqueness on the other side of the quote. Researchers also hope this research will be useful as a reference in researching the semiotic field. Researchers hope that many other elements in educational quotes can be found and analyzed. Research can be used for more student business results. Researchers also expect that people are more aware that education is the most important thing in life.

\section{REFERENCES}

Ala, T. F. (2011). A Semiotic Analysis in Mild Advertisement using Barthes Theory [Jakarta: Syarif Hidayatullah Islamic University.

Berek, A. (2018). Signs in Kawen Sai Ceremony of Tetun Tribe. RETORIKA: Jurnal Ilmu Bahasa, $4(2), 146-155$.

Collins, G. (2016). Language to Motivate Learning: The Power of Inspirational Quotes. Rising Tide, 1-22.

Jagalimu, R. U. ., \& Kasni, N. W. (2018). The Meaning of the Sign of Pasola Show in Waihura Village Wanokaka Sub-District, West Sumba Regency: A Study Of Semiotics. RETORIKA: Jurnal Ilmu Bahasa, 4(1), 1-9.

Latief, M. A. (2015). Research Method on Language Learning: An Introduction. Malang: Universitas Negeri Malang.

Layng, J. M. (2016). The Virtual Communication Aspect: A Critical review of Virtual Studies Over the last 15 Years. Journal of Literacy and Technology, 7(3), 172-218.
Mavers, D. (2004). Multimodal Design: The Semiotic Resources of children's graphic Representation. London.

Mayr, S. W. (2013). Reading Culture In TV Commercials A Semiotic Analysis of A TV Commercial For The Purpose of Teaching Culture to Foreign Language Students. Journal of Arts and Commerce, 2(1), 86-100.

Mazidah, N. L. (2018). A Semiotic Analysis of The Dump Trucks. Kediri: State Islamic Institute of Kediri.

Mirsarraf, M., Shairi, H., \& Ahmadpanah, A. (2017). International Conference on Innovations in Intelligent Systems and Applications (INISTA). IEEE.

Nassaji, H. (2015). Qualitative and Descriptive Research: Data Type versus Data Analysis. Sage Journal, 129-132.

Payuk, E. E. T., \& Zakrimal. (2020). Semiotic Analysis in Instagram Logo. IDEAS: Journal on English Language Teaching and Learning, Linguistics and Literature, 8(1), 332-339.

Putri, C. A., \& Arimbi, D. A. (2015). A Semiotic Analysis of the Representation of Indonesian Muslim Women on ANNISA Magazine's Front Covers. Jurnal UNAIR, 4(1), 48.

Rasyid, F. (2015). Metodologi Penelitian Sosial: Teori \& Praktek. Kediri: STAIN Kediri Press.

Shadiqi, A. (2014). Semiotic Analysis of South Park Cartoon Comedy Season I. Vivid: Journal of Language and Literature, 3(1).

Situmorang, Y. J. (2014). Semiotics Analysis On Color Symbols in Tobanese Batak Ulos. The Episteme Journal of Linguistics and Literature, 2(2), 1-15. 